\title{
Integration of three-dimensional ultrasonography in the prenatal diagnosis of amniotic band syndrome: A case report
}

\author{
Mert Turğal, Özgür Özyüncü, Aslıhan Yazıcıŏglu, Lütfü Sabri Önderoğlu \\ Department of Obstetrics and Gynecology, Maternal Fetal Medicine Unit, Hacettepe University Faculty of Medicine, \\ Ankara, Turkey
}

\begin{abstract}
Amniotic band syndrome is a rare disorder which is thought to be caused by early rupture of the amniotic membrane. The extent of the disease may vary from minor digital amputations to severe lethal anomalies. For many years in routine clinical practice, this syndrome has been diagnosed with two-dimensional ultrasonography. Evolving imaging techniques by means of three-dimensional ultrasonography gives the chance of early and accurate diagnosis of this devastating anomaly. By integrating three-dimensional ultrasonography to the suspected findings diagnosed in the two-dimensional ultrasonography allows us to predict possible outcomes and provides convenience in counselling. Herein we present a case of amniotic band syndrome diagnosed at 19 weeks of gestation with three-dimensional ultrasonography and pregnancy was terminated in the 20th week. Using three-dimensional ultrasonography in certain suspected foetal anomalies may provide the early diagnosis and more accurate knowledge about extent of the disease.(J Turk Ger Gynecol Assoc 2014; 15: 56-9)
\end{abstract}

Key words: Amniotic band, constriction band, three-dimensional ultrasonography, prenatal diagnosis

Received: 26 May, 2013

Accepted: 25 July, 2013

Available Online Date: 30 January, 2014

\section{Introduction}

Amniotic band syndrome is a rare disorder with an incidence ranging from 1 in 1300 to 1 in 15,000 (1). The cause is thought to be amniotic bands resulting from the early rupture of amniotic membranes and wrapping of the free amniotic bands around various foetal parts (2). Abnormal growth and, in severe cases, amputation of extremities may be observed. The disease has a very wide spectrum of anomalies from minor to lethal depending on involvement of the foetal parts, degree of constriction of the band and timing of the rupture of the amniotic membrane. Thus, the prognosis of the disease may vary from isolated digital amputation to severe lethal anomalies of the central nervous system, face and viscera (1).

Amniotic band syndrome may be detected by ultrasonography with the observation of asymmetrical limb deformities or defects and visualisation of the amniotic membranes wrapping around foetal portions (1). The most common defect is constriction bands around foetal extremities. Management of the disease may change from expectant management to the termination of pregnancy according to the severity of disease (1). Spontaneous resolution of amniotic bands was also described (3).
Here, we represent an amniotic band syndrome case with the involvement of all extremities, in which the diagnosis was confirmed with three-dimensional (3D) ultrasonography.

\section{Case Presentation}

A 29 year old woman, gravida 1 para 0 , was referred to our unit with the suspicion of foetal limb malformations. Her past medical and obstetric history was unremarkable. On the ultrasonographic examination of the foetus at the $19^{\text {th }}$ week of gestation, both lower extremities were observed to be swollen and oedematous. With a detailed examination of the amniotic cavity, multiple amniotic bands were observed to be wrapping around both foetal lower extremities above the ankles and the involvement of one hand (Figure 1). The other hand was observed to be free. Accompanying organ anomalies were not seen. In 3D ultrasonographic examination, constriction rings around the foetal limbs and distal to ring malformations of the foetal feet were observed (Figure 2). In colour Doppler evaluation of the foetal lower limbs, decreased blood flow was observed. The final diagnosis of foetal amniotic band syndrome was considered and the possible outcomes were discussed with the patient; termination of the pregnancy was decided upon. 
At the $20^{\text {th }}$ week, the pregnancy was terminated. In the postpartum evaluation of the foetus, constriction rings were observed around both lower limbs above the ankles and distal to this, the extremities were swollen and oedematous. It was also observed that all of the digits of the right hand and only two digits of the left hand were amputated (Figure 3). Further pathological examination could not be performed since the family did not consent to an autopsy due to their religious beliefs.
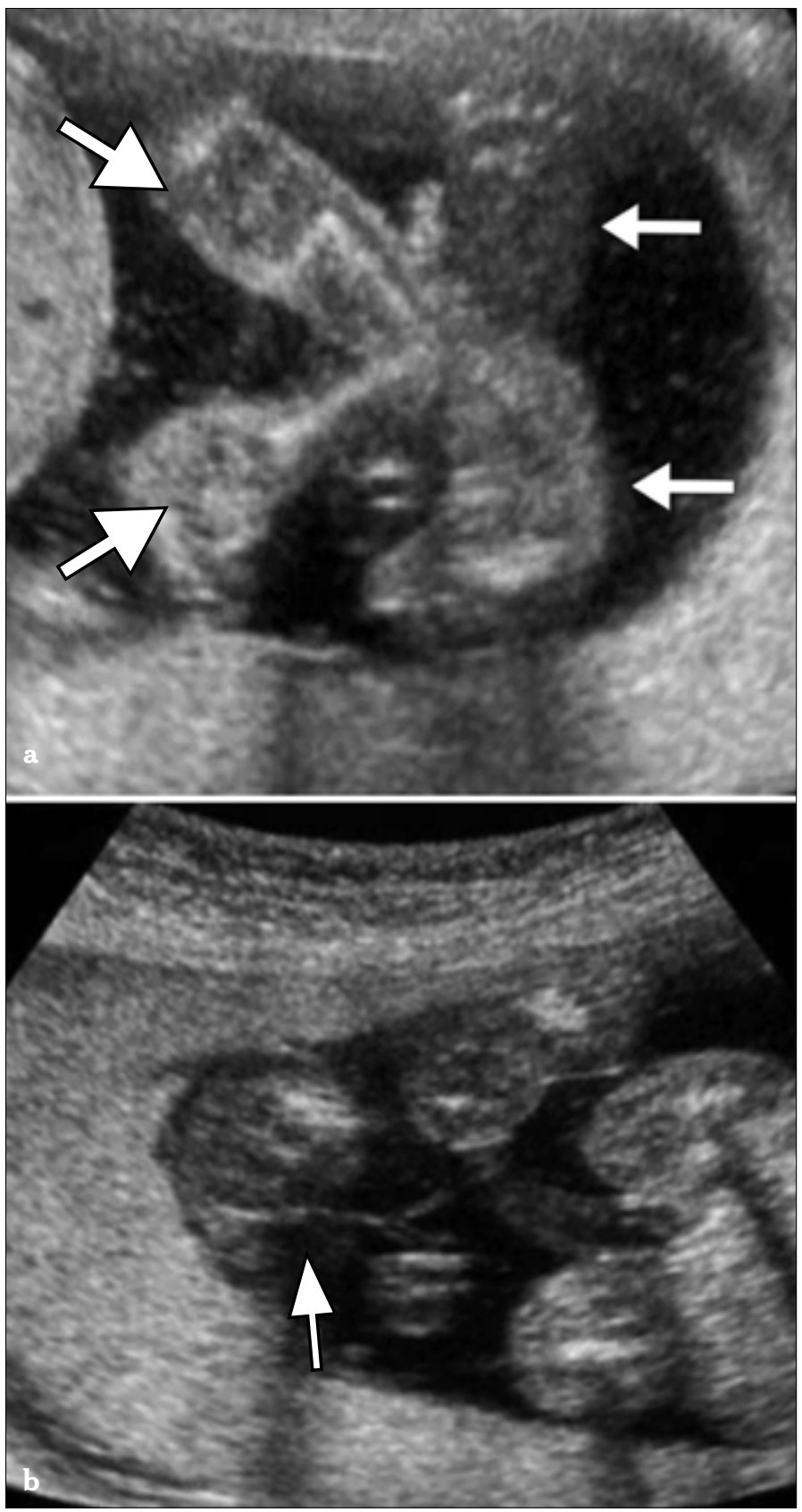

Figure 1. a, b. Ultrasonographic examination of the foetus. Thin white arrows show the deformed foetal feet. Thick white arrows identify the foetal lower limbs (a). White arrow indicates the amniotic band (b)
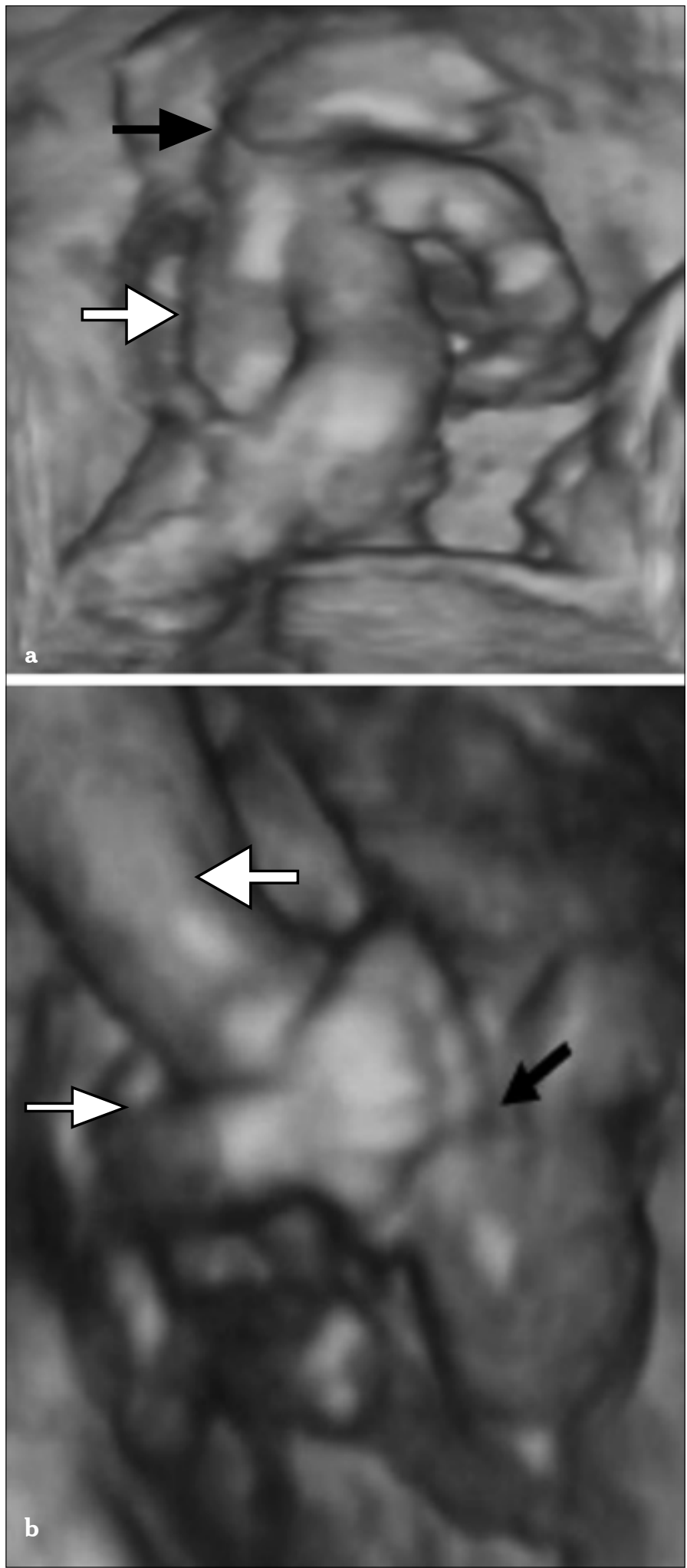

Figure 2. a, b. Three-dimensional examination of the foetus. Black arrow pointing to the constriction ring in the foetal foot. White arrow highlighting the foetal lower limb (a). Black arrow identifies the relationship of the foetal hand with the hand-foot-band complex. Thick white arrow points to the foetal hand and thin white arrow points to the oedematous foetal foot (b) 

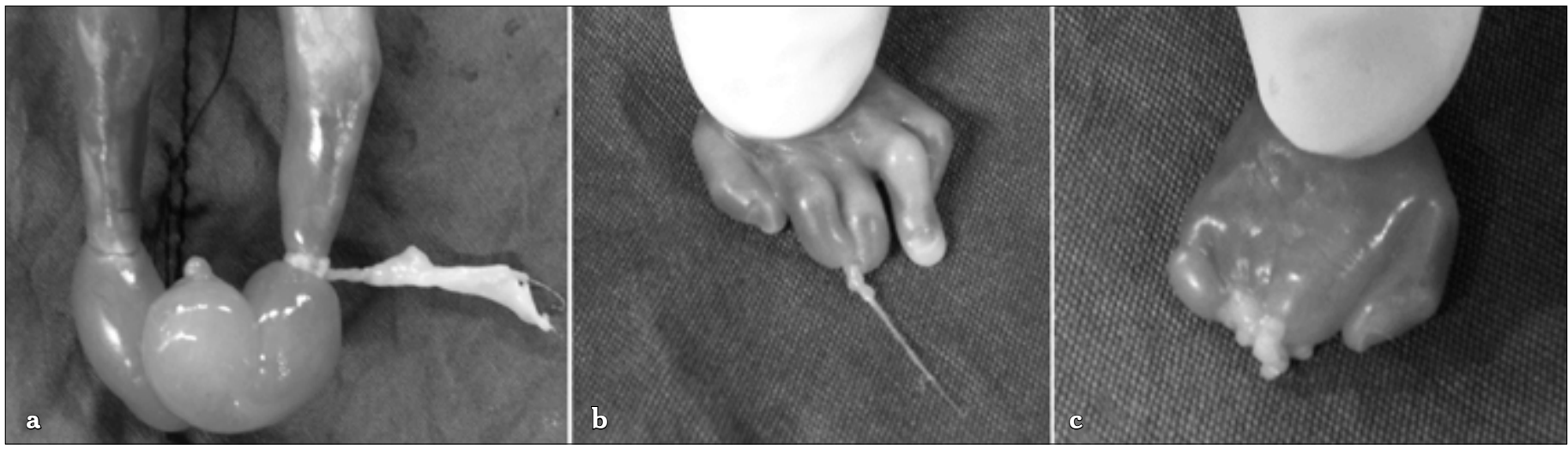

Figure 3. a-c. Examination of the foetus after delivery. Appearance of foetal feet (a). The left hand (b). Note that the $2^{\text {nd }}$ and $3^{\text {rd }}$ fingers were amputated from the distal phalanx. The right hand (c). Note that all of the fingers except the thumb were amputate

Table 1. Prenatal diagnosis of amniotic band syndrome with 3D (three-dimensional) ultrasound and postnatal outcome

\begin{tabular}{|c|c|c|c|c|c|}
\hline Authors & Year & $\begin{array}{l}\text { Gestational } \\
\text { age at } \\
\text { diagnosis }\end{array}$ & $\begin{array}{l}\text { Ultrasonographic } \\
\text { features }\end{array}$ & Postnatal features & Outcome \\
\hline Paladini et al. (7) & 2004 & 28 & $\begin{array}{l}\text { - Amniotic band at } \\
\text { supracondylar level of } \\
\text { left arm }\end{array}$ & $\begin{array}{l}\text { - Band detached spontaneously } \\
\text { from neonatal left arm }\end{array}$ & $\begin{array}{l}\text { No injury of left } \\
\text { arm }\end{array}$ \\
\hline Inubashiri et al. (9) & 2008 & 14 & $\begin{array}{l}\text { - Multiple amniotic } \\
\text { bands } \\
\text { - Acrania } \\
\text { - Kyphoscoliosis } \\
\text { - Gastroschisis } \\
\text { - Club-foot }\end{array}$ & $\begin{array}{l}\text { - Multiple amniotic bands } \\
\text { - Acrania } \\
\text { - Kyphoscoliosis } \\
\text { - Gastroschisis } \\
\text { - Club-foot }\end{array}$ & $\begin{array}{l}\text { Termination of } \\
\text { pregnancy }\end{array}$ \\
\hline Hata et al. (10) & 2011 & 13 & $\begin{array}{l}\text { - Multiple amniotic } \\
\text { bands } \\
\text { - Acrania } \\
\text { - Absence of fingers } \\
\text { - Amputation of } \\
\text { bilateral toes }\end{array}$ & $\begin{array}{l}\text { - Multiple amniotic bands } \\
\text { - Acrania } \\
\text { - Absence of right fingers } \\
\text { - Partial absence of left fingers } \\
\text { - Amputation of bilateral toes } \\
\text { - Amputation of bilateral toes }\end{array}$ & $\begin{array}{l}\text { Termination of } \\
\text { pregnancy }\end{array}$ \\
\hline Hata et al. (10) & 2011 & 15 & $\begin{array}{l}\text { - Multiple amniotic } \\
\text { bands } \\
\text { - Acrania } \\
\text { - Cleft lip } \\
\text { - Right hand syndactyly }\end{array}$ & $\begin{array}{l}\text { - Multiple amniotic bands } \\
\text { - Acrania } \\
\text { - Cleft lip } \\
\text { - Right hand syndactyly }\end{array}$ & $\begin{array}{l}\text { Termination of } \\
\text { pregnancy }\end{array}$ \\
\hline Nardozza et al. (8) & 2012 & 34 & $\begin{array}{l}\text { - Two amniotic bands } \\
\text { at right forearm }\end{array}$ & $\begin{array}{l}\text { - Bands detached surgical } \\
\text { procedure from neonatal right } \\
\text { forearm }\end{array}$ & $\begin{array}{l}\text { No injury of right } \\
\text { arm }\end{array}$ \\
\hline
\end{tabular}




\section{Discussion}

The occurrence of amniotic band syndrome is rare. The most commonly accepted theory to describe the pathogenesis is the early rupture of the amniotic membrane (2). With rupture, the amniotic membrane detaches from the chorion and fluid moves through the tear between the amnion and chorion. Meanwhile, some portions of the foetus may also exit through this tear. Then, the remaining free ends of the amniotic membranes entangle various body portions, causing constriction. As the foetus grows, the constriction ring tightens and the decreased venous return from the affected site causes oedema and swelling of the distal part. As a result, in severe cases, the clinical presentation is characterised by asymmetrical limb involvement accompanied by a short umbilical cord (4). Thus, the degree of involvement determines clinical presentation. However, some authors have challenged this theory, stating that it did not explain the involvement of some internal organs of the foetus (5). In the management of the amniotic band syndrome, foetoscopic laser surgery was also reported for the release of amniotic bands, but it is unclear whether release of the band also causes relaxation of the constriction ring. This approach may be beneficial in cases with isolated involvement when severe circulatory alterations had not occurred (6). Therefore, invasive procedures in treatment are still experimental.

The prenatal ultrasound detection of amniotic constriction bands around extremities has been described many times. This can be performed both by two-dimensional and three-dimensional ultrasonography. When giving information to the family about the prognosis and discussing the possible outcomes, a more accurate description of the extent of the disease is essential. The surface rendering mode of three-dimensional ultrasonongraphy allows spatial analysis of the foetus and amniotic bands, which provides superiority over two-dimensional ultrasonography. This helps families to have a better understanding of the severity of the syndrome and clinicians to provide more detailed counselling. In our case, the ultrasonographic examination revealed involvement of only three extremities, but after delivery, it was observed that all of the extremities were involved. We consider the fact that the fourth affected limb was not detected was the unsatisfactory aspect of our clinical practice.

In the literature, there have been five reported cases of amniotic band syndrome diagnosed by prenatal 3D/4D (four-dimensional) ultrasound, except for this report. The first case was reported by Paladini et al. (7), in which a 3D ultrasound was employed to characterise the anomaly at 28 weeks of gestation. Similarly, the last case was reported by Nardozza et al. (8), who diagnosed the case at 34 weeks gestation. Isolated arm injuries were diagnosed in these two case reports. Pregnancies were followed with serial ultrasonographic assessments and foetuses were born at term. Both neonates were discharged in good condition. Two other case reports have described three foetuses with amniotic band syndrome in the first trimester and early second trimester $(9,10)$. These three foetuses had multiple severe anomalies, such as acrania, kyphoscoliosis and gastroschisis, from constriction rings and all of the pregnancies were terminated due to these lethal anomalies. Details of the current and other reports are given in Table 1. Evolving imaging techniques are improving the prenatal diagnosis of foetal anomalies and providing us with a more accurate diagnosis of the extent of the anomaly. The 4D examination of the movement of extremities and relationship with the amniotic band provides us with a more precise extent of disease which is very important in determining prognosis. As a conclusion, we describe a case of amniotic band syndrome with involvement in all extremities. This case is one of the rare reports in the literature in which 3D ultrasound was used in the diagnosis of amniotic band syndrome as early as the $19^{\text {th }}$ week of pregnancy.

\section{Ethics Committee Approval: N/A}

Informed Consent: Informed consent was received from the participants of this study.

Peer-review: Externally peer-reviewed.

Author contributions: All of the authors contributed equally during the preparation of this manuscript.

Conflict of Interest: No conflict of interest was declared by the authors.

Financial Disclosure: The authors declared that this study received no financial support.

\section{References}

1. Marino T. Ultrasound abnormalities of the amniotic fluid, membranes, umbilical cord, and placenta. Obstet Gynecol Clin North Am 2004; 31: 177-200. [CrossRef]

2. Torpin T. Amniochorionic mesoblastic fibrous strings and amniotic bands. Associated constricting fetal anomalies or fetal death. Am J Obstet Gynecol 1965; 91: 65-75.

3. Pedersen TK, Thomsen SG. Spontaneous resolution of amniotic bands. Ultrasound Obstet Gynecol 2001; 18: 673-4. [CrossRef]

4. Api M, Görgen H, Fiçıcıoğlu C, Yorgancı C. Amniotic band syndrome: a case report. Perinatology Journal 1993; 1: 231-5.

5. Bronshtein M, Zimmer EZ. Do amniotic bands amputate fetal organs? Ultrasound Obstet Gynecol 1997; 10: 309-11. [CrossRef]

6. Keswani SG, Johnson MP, Adzick NS, Hori S, Howell LJ, Wilson $\mathrm{RD}$, et al. In utero limb salvage: fetoscopic release of amniotic bands for threatened limb amputation. J Pediatr Surg 2003; 38: 848-51. [CrossRef]

7. Paladini D, Foglia S, Sglavo G, Martinelli P. Congenital constriction band of the upper arm: the role of three-dimensional ultrasound in diagnosis, counseling and multidisciplinary consultation. Ultrasound Obstet Gynecol 2004; 23: 520-2. [CrossRef]

8. Nardozza LM, Araujo EJ, Caetano AC, Moron AF. Prenatal Diagnosis of Amniotic Band Syndrome in the Third Trimester of Pregnancy using 3D Ultrasound. J Clin Imaging Sci 2012; 2: 22. [CrossRef]

9. Inubashiri E, Hanaoka U, Kanenishi K, Yamashiro C, Tanaka H, Yanagihara T, et al. 3D and 4D sonographic imaging of amniotic band syndrome in early pregnancy. J Clin Ultrasound 2008; 36: 573-5. [CrossRef]

10. Hata T, Tanaka H, Noguchi J. 3D/4D sonographic evaluation of amniotic band syndrome in early pregnancy: a supplement to 2D ultrasound. J Obstet Gynaecol Res 2011; 37: 656-60. [CrossRef] 